\title{
Indian Ocean zonal mode activity in a multicentury integration of a coupled AOGCM consistent with climate proxy data
}

\author{
Thomas Mölg, ${ }^{1}$ Manuel Renold, ${ }^{2}$ Mathias Vuille, ${ }^{3}$ Nicolas J. Cullen, ${ }^{1}$ \\ Thomas F. Stocker, ${ }^{2,4}$ and Georg Kaser ${ }^{1}$ \\ Received 22 March 2006; revised 17 August 2006; accepted 21 August 2006; published 30 September 2006.
}

[1] The coupled atmosphere-ocean system over the Indian Ocean (termed Indian Ocean Zonal Mode, IOZM) and its activity over the past 200 years is analyzed in a paleoclimate simulation from a coupled atmosphere-ocean general circulation model (AOGCM). Validation shows that the AOGCM captures spatio-temporal patterns of sea surface temperature anomalies as well as the seasonal phase-locking feature of the IOZM. The period 1820-1880 exhibits a high frequency of climatically significant IOZM events, compared to a relatively low frequency in the 20th century. This shift in frequency provides a climate dynamics background for the interpretation of proxy data from East Africa, a region subjected to anomalously strong October-December precipitation during IOZM events. In the late 19th century, East African lakes had highstands (e.g., Lake Victoria) and its glaciers stable extents (e.g., Kilimanjaro), consistent with a wetter climate due to the higher frequency of IOZM events. Citation: Mölg, T., M. Renold, M. Vuille, N. J. Cullen, T. F. Stocker, and G. Kaser (2006), Indian Ocean zonal mode activity in a multicentury integration of a coupled AOGCM consistent with climate proxy data, Geophys. Res. Lett., 33, L18710, doi:10.1029/2006GL026384.

\section{Introduction}

[2] Coupled atmosphere-ocean systems are the dominant source of interannual climate variability, particularly in the tropics. In addition to the Pacific-centered El Niño, attention has recently focused on the coupled system in the Indian Ocean (IO), termed the Indian Ocean Zonal Mode (IOZM) [Saji et al., 1999; Webster et al., 1999]. An IOZM event typically begins in May/June with anomalous cooling in the tropical eastern IO, accompanied by moderate southeasterly wind anomalies. Over the next months, these anomalies intensify together with an anomalous warming of the tropical western IO, resulting in a complete reversal of the climatological zonal sea surface temperature (SST) gradient (now warmer in the western IO). Also, easterly anomalies evolve in the lower-tropospheric zonal wind field along the equator, and convection is enhanced (suppressed) over the western

\footnotetext{
${ }^{1}$ Tropical Glaciology Group, Department of Earth and Atmospheric Sciences, University of Innsbruck, Innsbruck, Austria.

${ }^{2}$ Climate and Environmental Physics, Physics Institute, University of Berne, Berne, Switzerland.

${ }^{3}$ Climate System Research Center, Department of Geosciences, University of Massachusetts, Amherst, Massachusetts, USA.

${ }^{4}$ Also at International Pacific Research Center, School of Ocean and Earth Science and Technology, University of Hawaii at Manoa, Honolulu, Hawaii, USA.
}

Copyright 2006 by the American Geophysical Union. 0094-8276/06/2006GL026384\$05.00 (eastern) IO. All these features peak around October, followed by a return to the mean state. This characteristic seasonal evolution with its feedback loops is called the seasonal phaselocking feature of the IOZM. The descriptions above define a positive IOZM (henceforth simply called IOZM), a negative one is characterized by reversed anomalies.

[3] One of the regions affected by strong IOZM events is East Africa (EA), where anomalously high precipitation is observed in the October-December (OND) rainy season [e.g., Webster et al., 1999; Black et al., 2003]. This is one potential reason why OND rains show a much higher interannual variability than the other rainy season in EA from March-May (MAM) [e.g., Mutai and Ward, 2000]. OND rainfall variability could have also played a key role in the longer-term climate history of EA over the past two centuries [Hastenrath, 2001]. Several proxy archives (lakes, lake sediments, glaciers) indicate this history was characterized by a sudden shift from wetter to drier conditions during 1880-1900 [e.g., Hastenrath, 2001], and the maintenance of the drier climate in the 20th century [e.g., Verschuren et al., 2000]. The same proxies show a strong sensitivity to present precipitation variability [e.g., Mölg and Hardy, 2004]. Most obviously, the shift manifested itself in the drop of lake levels [Nicholson and Yin, 2001] and in the onset of glacier recession in EA [e.g., Hastenrath, 1984; Osmaston, 1989; Mölg et al., 2003]. Information on low lake levels in the early 19th century suggests the relatively wet period only began between the 1820s and 1840s when the levels started to rise [Verschuren, 1999; Verschuren et al., 2000; Nicholson and Yin, 2001; Stager et al., 2005]. The observed contribution of the IO to OND rainfall variability therefore evokes a question: Have the large-scale circulation conditions forcing IOZM events been more frequent in that wet period, as indicated by historical information [Hastenrath, 2001]? The present paper addresses this issue, and explores IOZM activity over the past two centuries from a paleoclimate simulation with a coupled atmosphere-ocean general circulation model (AOGCM).

[4] The IOZM has been analyzed in AOGCM simulations previously, mainly to explore the link between El Niño and the IOZM [e.g., Yu and Lau, 2004; Cai et al., 2005] but also to demonstrate the strong impact of the IOZM on climate in EA [Behera et al., 2005]. Here, the primary goals are to (a) validate IOZM system dynamics in the AOGCM, and (b) see how IOZM activity simulated in time compares to the signals in proxy records from EA (as outlined above).

\section{Data and Methods}

[5] The AOGCM simulation has been conducted at the University of Berne with the Community Climate System 

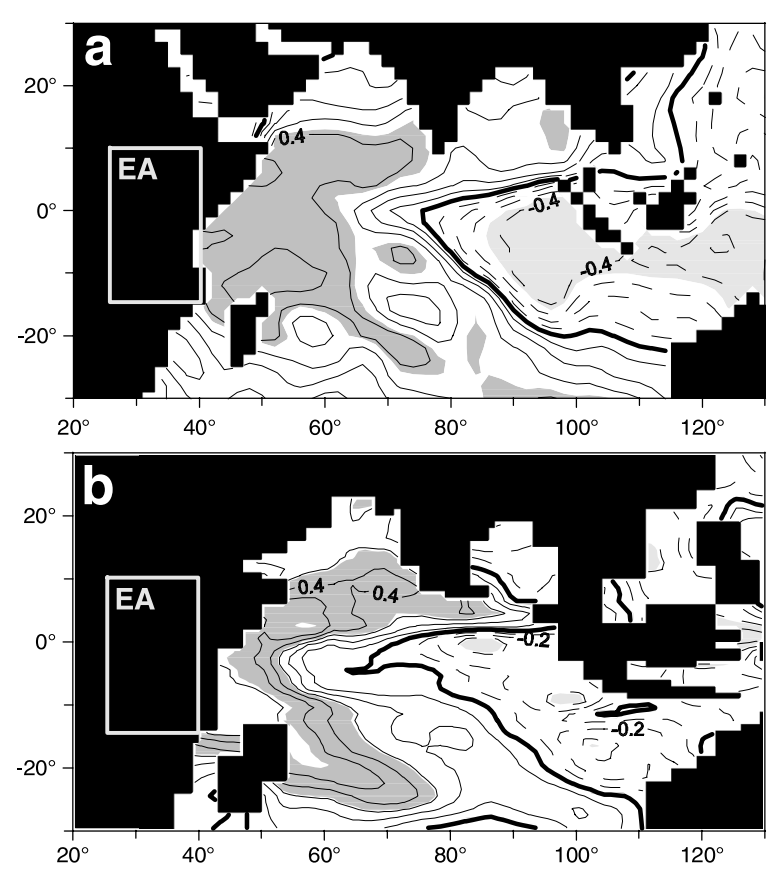

Figure 1. (a) Correlation field of September-November (SON) ERSST anomalies with CRU OND precipitation in EA (EA box: $25^{\circ}-40^{\circ} \mathrm{E} ; 10^{\circ} \mathrm{N}-15^{\circ} \mathrm{S}$ [cf. Mutai and Ward, 2000]), 1971-2000. The bold line separates positive and negative correlation zones (contour interval is 0.1 ), dark (light) shadings reveal areas of $p<0.05$ in the positive (negative) zone (based on $t$-statistics). (b) As in Figure 1a but for AOGCM results, 1951-1990. Note the different land mask due to the lower spatial resolution in the AOGCM.

Model, version 3 (CCSM3) [Collins et al., 2006], without the use of flux adjustments. From the starting point (AD 1500) the model was integrated up to 1990 by time-varying the solar constant, optical depth of the stratosphere (accounting for volcanic eruptions), and greenhouse gas (GHG) concentration. This forcing technique is described in detail by Yoshimori et al. [2005]. GHG data come from Etheridge et al. [1996, 1998], volcanic forcing data were constructed after Crowley [2000], and solar forcing data are based on work by Lean et al. [1995] and Crowley [2000]. The spatial representation of the atmospheric (ocean) component relies on a $3.75^{\circ}$ $\left(\sim 2.8^{\circ}\right.$, tropics $\left.\sim 0.9^{\circ}\right)$ horizontal grid, and 26 (25) levels in the vertical extending to $2.9 \mathrm{hPa}(5.4 \mathrm{~km}$ depth $)$. Here, output for the period 1800-1990 is analyzed for the region of interest (mainly tropical IO).

[6] To validate the AOGCM against 20th-century climate (section 3), three data sets of gridded observations are used. Monthly SST is obtained from version 2 of the Extended Reconstructed SST (ERSST) data set [Smith and Reynolds, 2004], while the zonal wind component is extracted from the NCEP-NCAR reanalysis [Kalnay et al., 1996]. Additionally, monthly land surface precipitation from the Climate Research Unit (CRU) data sets has been used [Mitchell and Jones, 2005].

[7] One way to illustrate the IOZM is to compute the correlation field of SST anomalies with OND precipitation averaged over the EA domain [e.g., Vuille et al., 2005], as shown in Figure 1a for present climate by use of the ERSST and CRU data sets. The resultant dipole pattern confirms the so-called Dipole Mode Index (DMI) established by Saji et al. [1999] to identify the IOZM, defined as the difference in SST anomaly between the western $\left(50^{\circ}-70^{\circ} \mathrm{E} ; 10^{\circ} \mathrm{N}-10^{\circ} \mathrm{S}\right)$ and eastern $\left(90^{\circ}-110^{\circ} \mathrm{E} ; 0^{\circ}-10^{\circ} \mathrm{S}\right) \mathrm{IO}$. To quantify the atmospheric manifestation of the IOZM, a zonal wind index (ZWI) has emerged as very effective [Hastenrath, 2001; Vuille et al., 2005]. It is defined as the area-averaged zonal wind component at $850 \mathrm{hPa}$ over the central $\mathrm{IO}\left(60^{\circ}-90^{\circ} \mathrm{E} ; 5^{\circ} \mathrm{N}-5^{\circ} \mathrm{S}\right)$. In addition to these indices, empirical orthogonal functions (EOFs) are employed in this study, to obtain main modes of SST variability.

\section{Results and Discussion}

[8] In a first step simple correlations have been calculated between IOZM-related parameters, to demonstrate their strong inter-dependence. Table 1 presents the highest coefficients for the observations, and compares them to the AOGCM fields. The validation period was chosen over 1951-90, because the number of stations in EA considered in the CRU interpolation method remains almost constant from the 1950s to 1990 s, and ERSST data show a persistent high skill after the World War II period [Smith and Reynolds, 2004]. The large-scale correlation (DMI-ZWI) is very similar in both data types, whereas the regional precipitation response in EA is smoothed in the AOGCM, also in terms of OND rainfall standard deviation (std. dev.). This is not surprising, as the topography of EA is inadequately resolved in AOGCMs to model observed precipitation variability [McHugh, 2005]. Overall, the AOGCM shows the same statistically significant relationships as the observations (Table 1), and both spatial pattern and amplitude of the SSTrainfall link are simulated reasonably well in the AOGCM (Figure 1b) compared to present observations (Figure 1a).

[9] To validate the model's ability in generating realistic SST variability in the tropical IO further, an EOF analysis has been applied to seasonally stratified SST anomalies simulated by the AOGCM [cf. Cai et al., 2005]. Figure 2 displays the results for the SON season, the time of the IOZM peak phase. As in observations [Saji et al., 1999], the leading mode of SST anomalies (EOF1) reflects a basin-wide uniform pattern, while the second mode (EOF2) exhibits an out-of-phase relation between the western and eastern $\mathrm{IO}$, representing the characteristic dipole structure of the IOZM. The EOF2 time series (of the expansion coefficient) correlates with the DMI at $r=0.94$. Still, negative loadings seem to penetrate further into the western IO than observations indicate, which is also evident by comparing the extents of the negative correlation zones in Figure 1. Thus, we considered an alternative model DMI with SST of the western pole averaged over the latitude band $10^{\circ} \mathrm{N}-0^{\circ}$ (instead of $10^{\circ} \mathrm{N}-10^{\circ} \mathrm{S}$ ). As this did not change the findings of this study, and the $r$ discussed above is very high (0.94), we have chosen to use

Table 1. Selected Correlation Coefficients and Standard Deviation for OND Precipitation (OND P) Over the Validation Period 1951-1990

\begin{tabular}{lcc}
\hline \multicolumn{1}{c}{ Criterion } & Gridded Observations & AOGCM \\
\hline OND P-SON ZWI & $-0.71^{\mathrm{a}}$ & $-0.61^{\mathrm{a}}$ \\
OND P-SON DMI & $0.76^{\mathrm{a}}$ & $0.43^{\mathrm{a}}$ \\
SON DMI-SON ZWI & $-0.72^{\mathrm{a}}$ & $-0.79^{\mathrm{a}}$ \\
std. dev. OND P, \% of mean & 20 & 9 \\
\hline
\end{tabular}

${ }^{\mathrm{a}} \mathrm{p}<0.01$ (based on a two-tailed $t$-test). 


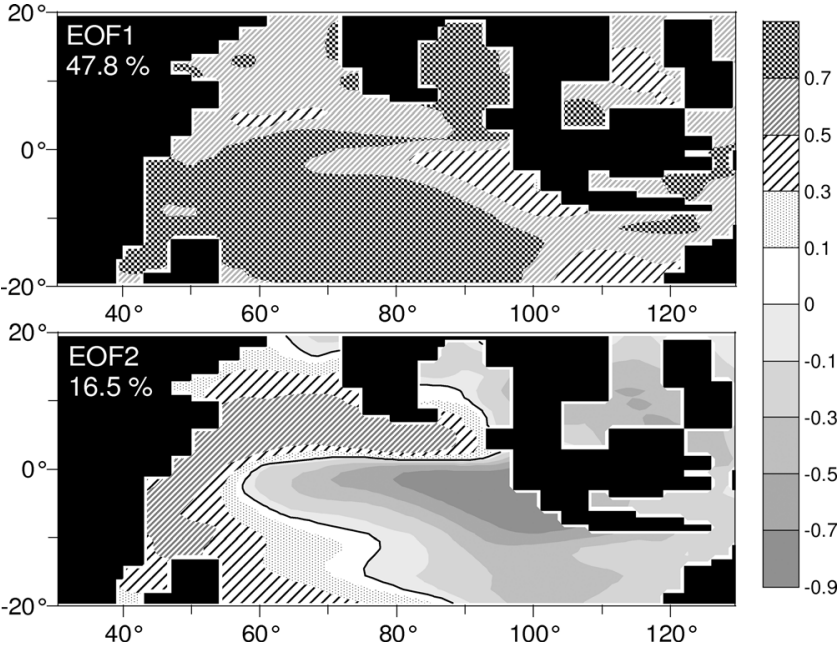

Figure 2. AOGCM pattern (spatial loadings) of (top) EOF1 and (bottom) EOF2 of SST anomalies $\left({ }^{\circ} \mathrm{C}\right)$ during SON, 1800-1990. The eigenvalues (in \% of explained total variance) are given in the upper-left corners. EOFs are rescaled by one standard deviation anomaly of the expansion coefficient.

the original definition of the DMI (section 2) for the remainder of the paper.

[10] Another crucial point is how well the seasonal-phase locking feature of the IOZM is captured by the AOGCM. Figure 3 presents a composite analysis of relevant parameters, showing deviations of the mean annual cycle during strong IOZM events from the mean annual cycle 1800-1990. Similarly to work by Iizuka et al. [2000], an IOZM event is defined as strong if the SON DMI exceeds +1.25 std.dev. of the entire SON DMI time series. This threshold proved to be the most useful in the scatterplot of ERSST versus CRU observations over the validation period. The plot (not shown) indicates that a SON DMI $>+1.25$ std.dev. coincides with a high probability of OND rains in EA to deviate more than +1 std.dev. from their mean. On the other side, a clear relationship between a negative DMI and OND rain deficit does not arise, consistent with Black et al. [2003, cf. their Figure 8]. In total, 26 strong IOZM events occur in the analyzed AOGCM data (191 years). During these events, the

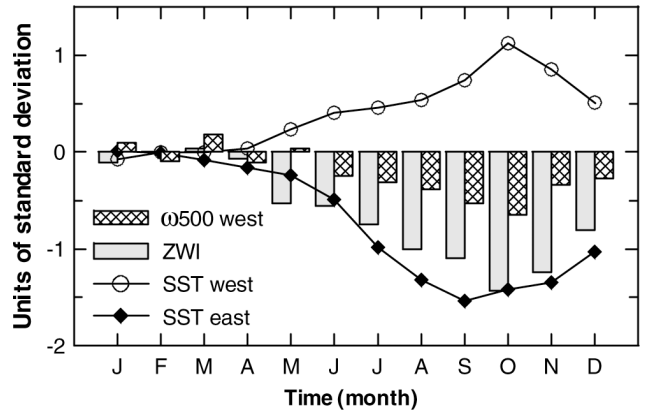

Figure 3. AOGCM composite time series of IOZMrelated parameters during strong IOZM events. The mean annual cycle (1800-1990) is removed from the series, and each month normalized by its standard deviation. $\omega 500$ is omega vertical velocity at $500 \mathrm{hPa}$ averaged over the western SST pole, an indicator of convection. Other abbreviations as in the text.

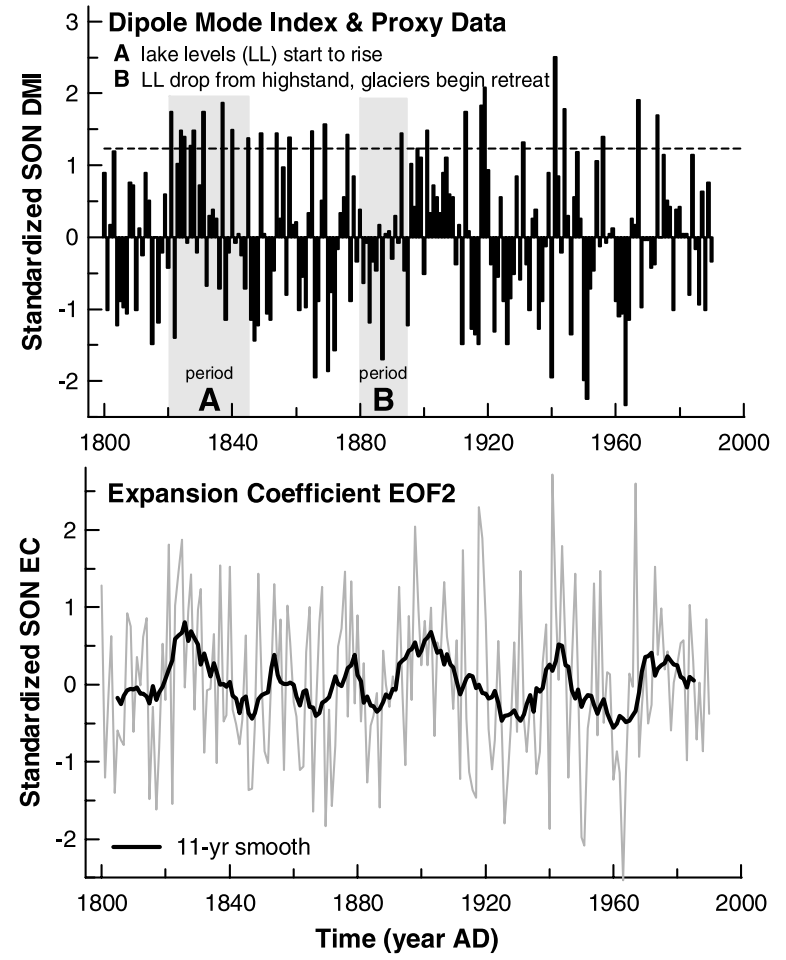

Figure 4. AOGCM time series of (top) SON DMI (dashed line indicates threshold which defines a strong IOZM) with grey rectangles illustrating the range of two periods when drastic changes of proxy phenomena occurred [Hastenrath, 1984, 2001; Osmaston, 1989; Verschuren, 1999; Verschuren et al., 2000; Nicholson and Yin, 2001; Stager et al., 2005], and (bottom) expansion coefficient (EC) of EOF2.

seasonal-phase locking feature is evident in the model (Figure 3), starting in late boreal spring and peaking around September/October (including increased convection over the western IO, cf. introduction). The positive anomaly in the western SST pole is not as strong as in observations due to the excessive westward extension of the cold SST anomaly (Figure 2, bottom), also noted by Iizuka et al. [2000] and visible in the EOF analysis by Cai et al. [2005]. This seems to be a general shortcoming of AOGCMs, which Iizuka et al. [2000] attribute to deficits in ocean-mixed layer physics. It may also explain why the negative SST anomaly over the eastern pole (Figure 3), and thus the negative ZWI anomaly, do not decrease as quickly after their peaks as in observations.

[11] The simulated time series of the SON DMI is depicted in Figure 4 (top). A high frequency of strong IOZM events is found in 1820-1880 $(\mathrm{n}=15)$, while only nine events appear in the 20th century. Accordingly, almost $80 \%$ of the SON ZWI during 1820-1880 indicate an easterly wind component, compared to $68 \%$ for the 20th century (not shown). Between those two periods, a marked absence of positive IOZM activity is apparent (ca. 1880-1895), a factor probably involved in the climate shift detected from proxy data (cf. Figure 4, top, and section 1). Negative activity seems enhanced in the 20th century. However, as there is no clear relation between negative DMI and negative OND rain anomalies, this cannot be interpreted as intensified drought. In this context, drought during the 20th century may rather be understood as extreme OND rains that have become less frequent. For the validation period, the strong IOZM events observed in the 1960s are delayed a few 
years in the AOGCM, whereas the weak positive activity in the 1980s agrees well with observations [Saji et al., 1999]. The higher frequency of strong IOZM events in the 19th century can be illustrated further by the time series of EOF2 which represents the IOZM (Figure 4, bottom). Viewing the decadal smooth, the frequency of the mode's oscillation is lower during the 20th century, with longer cycle durations ( $\sim 30-40$ yrs $)$ than in the 19th century ( $\sim 20-30$ yrs).

[12] Cai et al. [2005] have emphasized that most IOZM events in their AOGCM occur unrealistically one year after an El Niño peaks. A time series analysis of the DMI and the Niño3.4-index from our data does not point to this behavior. Only a few events peak one year after an El Niño does, but the majority $(>75 \%)$ peaks in the same year as or independently of El Niño, which is in agreement with observations [Saji et al., 1999].

\section{Concluding Remarks}

[13] In accordance with Table 1, the regional precipitation response to the more frequent IOZM events during 18201880 is not as pronounced in the AOGCM as it actually might have been. The grid points correlating most strongly with the SON DMI (near-coastal East Africa) do show an increase in mean OND rainfall over $1820-1880$, but it is mostly small (3-5\% on average). A higher horizontal resolution in the AOGCM [cf. Behera et al., 2005] or nesting of a regional climate model with detailed representation of the topography may improve this response effect. For instance, idealized experiments of atmospheric flow past the Kilimanjaro massif elucidate how the mountain modifies convective cell structure at times of increased moisture advection [Mölg et al., 2006].

[14] Nicholson and Yin [2001] estimate that annual rainfall over Lake Victoria was $\sim 17 \%$ higher during $1858-1878$ than the 20th century mean, and it is known that conditions in October and November alone account for $\sim 50 \%$ of interannual variability [Nicholson, 2000]. Still, one may wonder how, and if, the less variable MAM rains influenced the wetter period in the 19th century. MAM rains show a largescale association mainly with El Niño [Indeje et al., 2000], the activity of which may change over centennial time scales as well.

[15] A higher frequency of strong IOZM events between 1820 and 1880, as found in this study, provides at least one consistent mechanism that may have contributed to a wetter period centered around 1850/1860. Timing and duration of this higher frequency correspond to the timing of two shorter periods for which drastic changes in environmental proxies have been reported (cf. Figure 4, top, and section 1). Our finding thus provides a climate dynamics framework for these proxies, but also for historical-source proxy data [Nicholson, 2000; Hastenrath, 2001] which suggest the same scenario: the 19th-century wet period in EA may reflect primarily climatic conditions that have shown less persistence during the 20th century; conditions favorable to higher lake stands and stable glaciers.

[16] Acknowledgments. This study is funded by the Austrian Science Foundation (FWF) under grant P17415-N10 and by the Tyrolean Science Foundation (Tiroler Wissenschaftsfonds). AOGCM simulations are supported by the National Centre for Competence in Research (NCCR Climate) and the Swiss National Science Foundation (NSF) and are conducted at the Swiss National Supercomputing Centre (CSCS). M.V. is supported by NSF (ATM-0317693) and NOAA (03OAR4310046). This is IPRC contribution 386 and a contribution to the Centre for Climate and Cryosphere at Innsbruck University.

\section{References}

Behera, S. K., et al. (2005), Paramount impact of the Indian Ocean dipole on the East African short rains: A GCM study, J. Clim., 18, 4514-4530.

Black, E., J. Slingo, and K. Sperber (2003), An observational study of the relationship between excessively strong short rains in coastal East Africa and Indian Ocean SST, Mon. Weather Rev., 131, 74-94.

Cai, W., H. H. Hendon, and G. Meyers (2005), Indian Ocean dipolelike variability in the CSIRO Mark 3 coupled climate model, J. Clim., 18 , $1449-1468$

Collins, W. D., et al. (2006), The Community Climate System Model: CCSM3, J. Clim., 19, 2122-2142.

Crowley, T. J. (2000), Causes of climate change over the past 1000 years, Science, 289, 270-277

Etheridge, D. M., L. P. Steele, R. L. Langenfelds, R. J. Francey, J. M. Barnola, and V. I. Morgan (1996), Natural and anthropogenic changes in atmospheric $\mathrm{CO}_{2}$ over the last 1000 years from air in Antarctic ice and firn, J. Geophys. Res., 101, 4115-4128.

Etheridge, D. M., L. P. Steele, R. J. Francey, and R. L. Langenfelds (1998), Atmospheric methane between 1000 A.D. and present: Evidence of anthropogenic emissions and climatic variability, J. Geophys. Res., 103 $15,979-15,994$

Hastenrath, S. (1984), The Glaciers of Equatorial East Africa, Springer, New York.

Hastenrath, S. (2001), Variations of East African climate during the past two centuries, Clim. Change, 50, 209-217.

Iizuka, S., T. Matsuura, and T. Yamagata (2000), The Indian Ocean SST dipole simulated in a coupled general circulation model, Geophys. Res. Lett., 27, 3369-3372.

Indeje, M., F. H. M. Semazzi, and L. J. Ogallo (2000), ENSO signals in East African rainfall seasons, Int. J. Climatol., 20, 19-46.

Kalnay, E., et al. (1996), The NCEP/NCAR 40-year reanalysis project, Bull. Am. Meteorol. Soc., 77, 437-471.

Lean, J., J. Beer, and R. Bradley (1995), Reconstruction of solar irradiance since 1610: Implications for climate change, Geophys. Res. Lett., 22, $3195-3198$

McHugh, M. J. (2005), Multi-model trends in East African rainfall associated with increased $\mathrm{CO}_{2}$, Geophys. Res. Lett., 32, L01707, doi:10.1029/ 2004GL021632.

Mitchell, T. D., and P. D. Jones (2005), An improved method of constructing a database of monthly climate observations and associated highresolution grids, Int. J. Climatol., 25, 693-712.

Mölg, T., and D. R. Hardy (2004), Ablation and associated energy balance of a horizontal glacier surface on Kilimanjaro, J. Geophys. Res., 109, D16104, doi:10.1029/2003JD004338

Mölg, T., C. Georges, and G. Kaser (2003), The contribution of increased incoming shortwave radiation to the retreat of the Rwenzori glaciers, East Africa, during the 20th century, Int. J. Climatol., 23, 291-303.

Mölg, T., N. J. Cullen, D. R. Hardy, and G. Kaser (2006), Tropical glaciers in the context of climate change and society: Focus on Kilimanjaro (East Africa), in The Darkening Peaks: Glacial Retreat in Scientific and Social Context, edited by B. Orlove, E. Wiegandt, and B. Luckman, Univ. of Calif. Press, Berkeley, in press.

Mutai, C. C., and M. N. Ward (2000), East African rainfall and the tropical circulation/convection on intraseasonal to interannual timescales, J. Clim., $13,3915-3939$

Nicholson, S. E. (2000), The nature of rainfall variability over Africa on time scales of decades to millenia, Global Planet. Change, 26, 137-158.

Nicholson, S. E., and X. Yin (2001), Rainfall conditions in equatorial East Africa during the nineteenth century as inferred from the record of Lake Victoria, Clim. Change, 48, 387-398.

Osmaston, H. (1989), Glaciers, glaciations and equilibrium line altitudes on Kilimanjaro, in Quarternary and Environmental Research on East African Mountains, edited by W. C. Mahaney, pp. 7-30, A. A. Balkema, Brookfield, Vt.

Saji, H. H., B. N. Goswami, P. N. Vinayachandran, and T. Yamagata (1999), A dipole mode in the tropical Indian Ocean, Nature, 401, $360-363$.

Smith, T. M., and R. W. Reynolds (2004), Improved extended reconstruction of SST (1854-1997), J. Clim., 17, 2466-2477.

Stager, J. C., D. Ryves, B. F. Cumming, L. D. Meeker, and J. Beer (2005), Solar variability and the levels of Lake Victoria, East Africa, during the last millennium, J. Paleolimnol., 33, 243-251.

Verschuren, D. (1999), Influence of depth and mixing regime on sedimentation in a small, fluctuating tropical soda lake, Limnol. Oceanogr., 44, 1103-1113. 
Verschuren, D., K. R. Laird, and B. F. Cumming (2000), Rainfall and drought in equatorial east Africa during the past 1,100 years, Nature, 403, 410-414.

Vuille, M., M. Werner, R. S. Bradley, R. Y. Chan, and F. Keimig (2005), Stable isotopes in East African precipitation record Indian Ocean zonal mode, Geophys. Res. Lett., 32, L21705, doi:10.1029/2005GL023876.

Webster, P. J., A .M. Moore, J. P. Loschnigg, and R. R. Leben (1999), Coupled ocean-atmosphere dynamics in the Indian Ocean during $1997-$ 98, Nature, 401, 356-360.

Yoshimori, M., T. F. Stocker, C. C. Raible, and M. Renold (2005), Externally forced and internal variability in ensemble climate simulations of the Maunder Minimum, J. Clim., 18, 4253-4270.
Yu, J., and K. M. Lau (2004), Contrasting Indian Ocean SST variability with and without ENSO influence: A coupled atmosphere-ocean GCM study, Meteorol. Atmos. Phys., 90, 179-191.

N. J. Cullen, G. Kaser, and T. Mölg, Tropical Glaciology Group, Department of Earth and Atmospheric Sciences, University of Innsbruck, Innrain 52, A-6020 Innsbruck, Austria. (thomas.moelg@uibk.ac.at)

M. Renold and T. F. Stocker, Climate and Environmental Physics, Physics Institute, University of Berne, Sidlerstraße 5, CH-3012 Berne, Switzerland.

M. Vuille, Climate System Research Center, Department of Geosciences, University of Massachusetts, 611 North Pleasant Street, Amherst, MA 01003-9297, USA. 